\title{
HUBUNGAN PENGETAHUAN PERSONAL HYGIENE DENGAN GEJALA PENYAKIT KULIT PADA PEMULUNG DI TEMPAT PEMBUANGAN AKHIR SAMPAH SUWUNG DENPASAR TAHUN 2018
}

\section{Komang Juli Angriyasa', I Made Bulda Mahayana², Moch. Choirul Hadi ${ }^{3}$}

\begin{abstract}
The level of an individual's education has a big contribution towards the mindset and health problems. The knowledge regarding personal hygiene is necessary to improve the health and behaviour of the ragpickers at Suwung landfill in preventing the symptoms of skin diseases. The purpose of this study was to determine the relationship of personal hygiene knowledge with the skin disease symptoms on ragpickers.

This research was an analytical survey conducted through interview method with cross-sectional approach. The sample size was 70 ragpickers at Suwung landfill. The result of ragpickers' knowledge at Suwung landfill was 15,7\% of good, 45, 7\% of medium, and 38,6\% of bad. The research found $54.3 \%$ samples had skin disease symptoms while $45.7 \%$ were negative. It was found that symptoms of skin diseases experienced such as itching, bumps, skin redness and scaly skin. From Chi-Square test results obtained p-value $=0.029<a(0.05)$, means the knowledge of personal hygiene and the skin disease symptoms on the ragpickers had a significant relationship, with a weak level of relationship (CC value=0,304). The conclusion, there was a relationship between personal hygiene knowledge and skin disease symptoms on ragpickers at the Suwung Landfill.
\end{abstract}

Keywords : knowledge, personal hygiene, skin disease

Kesehatan merupakan hak asasi manusia dan salah satu unsur kesejahteraan yang harus diwujudkan. Sedangkan menurut Undang- Undang Kesehatan No. 36 tahun 2009 kesehatan adalah keadaaan sehat baik secara fisik, mental, spiritual maupun sosial.

Personal Hygiene berasal dari bahasa Yunani yaitu personal yang artinya perorangan dan hygiene memiliki arti sehat. Jadi personal hygiene atau kebersihan diri adalah suatu tindakan untuk memelihara kebersihan atau kesehatan seseorang untuk kesehjateraan fisik dan psikis. Pemeliharaan personal hygiene diperlukan untuk kenyamanan individu, keamanan dan kesehatan. Salah satu jenis pekerjaan yang kadang mengabaikan personal hygiene tersebut adalah pemulung.

Pemulung adalah orang yang bekerja mengambil barang-barang bekas atau sampah tertentu untuk diproses daur ulang. Pemulung juga telah membantu mengurangi biaya pemerintah untuk pengumpulan, pengangkutan, dan pengolahan sampah dari masyarakat. Pekerjaan memulung yang selalu berhubungan dengan sampah menimbulkan pandangan bahwa cara hidup pemulung adalah cara hidup yang tidak sehat. Apabila dilihat dari segi kesehatan, pemulung memiliki risiko yang sangat tinggi untuk terkena penyakit. Lingkungan dan tempat kerja yang tidak kondusif serta kotor, kemungkinan besar pemulung dapat 
terjangkit berbagai macam penyakit, seperti batuk, gatal-gatal, diare, dan lain-lain. Dari segi keselamatan kerja, pemulung juga memiliki risiko yang cukup tinggi untuk mengalami kecelakaan karena pemulung melakukan kontak langsung dengan sampah (1).

Sampah adalah barang-barang atau sesuatu benda yang sudah tidak terpakai lagi baik berasal dari rumahrumah maupun sisa-sisa proses industri. Dalam kehidupan seharihari sampah yang dihasilkan masyarakat terdiri dari berbagai macam, seperti sampah basah (garbage) atau sampah organik yang sangat mudah mengurangi atau membusuk seperti sisa-sisa makanan, dan sampah kering (rubbish) atau sampah anorganik yang sulit membusuk, dimana kesemua jenis sampah ini masing-masing mempunyai kontribusi yang sangat besar terjadinya pencemaran lingkungan dan dapat menyebabkan terjadinya penyakit (2).

Tempat pembuangan akhir (TPA) sampah merupakan tempat dimana sampah mencapai tahap akhir dalam proses pengelolaannya, yaitu sejak mulai timbul dari sumber sampah, pengumpulan, pemindahan, pengangkutan dan pembuangan.

Salah satu tempat pembuangan akhir sampah yang ada di Bali yaitu adalah Tempat Pembuangan Akhir sampah Suwung yang terletak di Desa Suwung Kauh Kecamatan Denpasar Selatan Kota Denpasar. TPA sampah Suwung Denpasar berdiri pada tahun 1986 yang awalnya dikelola oleh Dinas Kebersihan dan Pertamanan Kota Denpasar. TPA sampah Suwung Denpasar merupakan tempat pembuangan akhir yang memiliki luas wilayah sekitar 40 hektar dimana dalam sehari menampung kurang lebih 1.500 ton sampah yang di dominasi oleh sampah rumah tangga yang berasal dari warga Kota Denpasar dan sebagian dari Kabupaten Badung, Kabupaten Gianyar dan Kabupaten Tabanan.

TPA sampah Suwung Denpasar banyak dijumpai para pemulung yang melakukan aktivitas dan sekaligus tinggal di sekitar area TPA. Aktivitas atau pekerjaan sehari-hari pemulung yaitu memilih, memungut dan mengumpulkan sampah atau barang bekas yang masih dapat dimanfaatkan dan barang yang dapat diolah kembali untuk dijual.

Hasil penelitian Saputra (3) terhadap pemulung terkait dengan identifikasi bakteri pada swab tangan pemulung di TPA sampah Suwung Denpasar tahun 2016. Perilaku pemulung di TPA sampah Suwung termasuk ke dalam kategori yang buruk yang dominan meliputi tidak menggunakan sarung tangan pada saat bekerja (73\%), tidak ada yang menggunakan sarung tangan sekali pakai $(100 \%)$ dan tidak memahami prosedur cuci tangan yang baik dan benar (97\%).

Berdasarkan hasil survei pendahuluan terhadap 30 pemulung menurut karakteristik umur yang berbeda-beda dan tingkat pendidikan serta lama kerja yang berbeda. Hasil observasi menunjukkan bahwa pemulung ketika bekerja kurang menjaga kebersihan dirinya, antara lain tidak menggunakan alat pelindung diri pada saat bekerja seperti sepatu boot, masker dan sarung tangan. Hasil wawancara didapatkan $90 \%$ pemulung di TPA sampah Suwung Denpasar mempunyai riwayat penyakit kulit. Sedangkan keluhan lainnya seperti batuk, pilek dan kepala pusing. 
Selama bekerja megumpulkan sampah para pemulung di TPA sampah Suwung Denpasar hanya menggunakan sepatu kain memilah sampah dan hanya $50 \%$ yang menggunakan sepatu boot serta pakaian lengan panjang dan menggunakan sarung tangan pada saat memilah sampah. Selain itu hanya $50 \%$ pemulung ada yang menggunakan topi ada juga yang tidak menggunakan penutup kepala.

Berdasarkan Data 10 besar penyakit tertinggi di seluruh Puskesmas di Provinsi Bali tahun 2016, risiko dan dampak kesehatan yang paling umum pada pemulung yaitu penyakit kulit. Kasus penyakit kulit berada pada peringkat ke tujuh dengan total penderita 37.356 orang. Sedangkan berdasarkan data dari Puskesmas IV Denpasar Selatan tahun 2016 pada wilayah kerjanya diketemukan kasus penyakit kulit berada pada urutan ke tujuh dengan total 994 orang.

Tujuan khusus dari penelitian ini adalah (a) Mengukur pengetahuan personal hygiene pemulung di Tempat Pembuangan Akhir sampah Suwung Denpasar.

(b) Mengetahui Gejala penyakit kulit pada pemulung di Tempat Pembuangan Akhir sampah Suwung Denpasar. (c) Menganalisis hubungan antara pengetahuan personal hygiene dengan gejala penyakit kulit pada pemulung di TPA sampah Suwung Denpasar.

\section{Metode}

Jenis penelitian ini adalah penelitian survei analitik dengan pendekatan cross sectional dimana variabel sebab atau risiko dan akibat atau kasus yang terjadi pada objek penelitian diukur atau dikumpulkan dalam waktu bersamaan (4). Tempat penelitian ini dilakukan di TPA sampah Suwung Denpasar dan waktu pelaksanaan dilakukan pada bulan Maret sampai dengan bulan Juni 2018. Metode yang digunakan dalam penelitian ini adalah wawancara dan pengamatan. Jumlah dan besar sampel dalam penelitian ini yaitu 70 pemulung dengan menggunakan metode sampling random (accidental sampling) yaitu secara tidak sengaja atau kebetulan bertemu (acak).

\section{Hasil Penelitian}

1. Distribusi pengetahuan pemulung menurut kategori pengetahuan personal hygiene

Tabel 1

Distribusi Kategori Pengetahuan Personal Hygiene Pemulung

\begin{tabular}{lll}
\hline Pengetahuan & Jumlah & $\begin{array}{c}\text { Presentase } \\
(\%)\end{array}$ \\
\hline Buruk & 27 & 38,6 \\
Sedang & 32 & 45,7 \\
Baik & 11 & 15,7 \\
Total & 70 & 100 \\
\hline
\end{tabular}

Berdasarkan data dari tabel 1 di atas menunjukkan bahwa hasil wawancara dengan menggunakan koesioner, distribusi kategori pengetahuan pemulung dari 70 orang, responden dengan tingkat pengetahuan kategori sedang paling banyak sebesar 32 orang $(45,7 \%)$ dan yang paling sedikit responden dengan tingkat pendidikan kategori baik sebesar 11 orang $(15,7 \%)$. 
2. Distribusi menurut kategori gejala penyakit kulit pada pemulung

Tabel 2

Distribusi Kategori Gejala Penyakit Kulit pada Pemulung

\begin{tabular}{ccc}
\hline $\begin{array}{c}\text { Gejala Penyakit } \\
\text { Kulit }\end{array}$ & $\begin{array}{c}\text { Jumlah } \\
(\mathrm{N})\end{array}$ & $\begin{array}{c}\text { Presentase } \\
(\%)\end{array}$ \\
\hline Ada & 38 & $54,3 \%$ \\
Tidak Ada & 32 & $45,7 \%$ \\
\hline Total & 79 & 100.0 \\
\hline
\end{tabular}

Dari tabel 2 di atas menunjukkan bahwa pemulung yang ada gejala penyakit kulit lebih banyak yaitu 38 orang $(54,3 \%)$ daripada pemulung tidak ada mengalami gejala penyakit kulit yaitu 32 orang $(45,7 \%)$. Hal ini menunjukkan bahwa pemulung di TPA sampah Suwung Denpasar lebih banyak mengalami gejala penyakit kulit.

3. Analisis hubungan pengetahuan personal hygiene dengan gejala penyakit kulit pada pemulung di TPA sampah Suwung Denpasar.

Tabel 3

Analisis Hubungan Pengetahuan

Personal Hygiene dengan Gejala Penyakit

\begin{tabular}{|c|c|c|c|c|c|}
\hline \multirow{2}{*}{$\begin{array}{c}\text { Pengeta } \\
\text { huan }\end{array}$} & \multicolumn{2}{|c|}{$\begin{array}{c}\text { Gejala Penyakit } \\
\text { Kulit }\end{array}$} & \multirow{2}{*}{$\begin{array}{c}\text { Jumla } \\
\mathbf{h}\end{array}$} & \multirow{2}{*}{$\begin{array}{c}\mathbf{P} \\
\text { Val } \\
\text { ue }\end{array}$} & \multirow{2}{*}{$\begin{array}{c}\mathrm{CC} \\
\mathrm{Val} \\
\text { ue }\end{array}$} \\
\hline & Ada & $\begin{array}{c}\text { Tidak } \\
\text { Ada }\end{array}$ & & & \\
\hline Buruk & $\begin{array}{c}20 \\
(28,6 \%)\end{array}$ & $\begin{array}{c}7 \\
(10,0 \%)\end{array}$ & $\begin{array}{c}27 \\
(38,7 \%)\end{array}$ & & \\
\hline Sedang & $\begin{array}{c}14 \\
(20,0 \%)\end{array}$ & $\begin{array}{c}18 \\
(25,7 \%)\end{array}$ & $\begin{array}{c}38 \\
(45,7 \%)\end{array}$ & $\begin{array}{c}\mathbf{0 , 0 2} \\
9\end{array}$ & $\begin{array}{c}0,30 \\
4\end{array}$ \\
\hline Baik & $\begin{array}{c}4 \\
(5,7 \%)\end{array}$ & $\begin{array}{c}7 \\
(10,0 \%)\end{array}$ & $\begin{array}{c}5 \\
(15,7 \%)\end{array}$ & & \\
\hline Total & 38 & 32 & $\begin{array}{c}70 \\
(100 \%)\end{array}$ & & \\
\hline
\end{tabular}

Berdasarkan data dari tabel 3 di atas mendapatkan hasil dari 70 orang pemulung yang memiliki pengetahuan buruk ada gejala penyakit kulit adalah 20 orang $(28,6 \%)$ dan pemulung yang memiliki pengetahuan buruk dan tidak ada gejala penyakit kulit sebanyak 7 orang $(10,0 \%)$. Pemulung yang memiliki pengetahuan sedang yang ada gejala penyakit kulit sebanyak 14 orang $(20,0 \%)$ dan pemulung yang memiliki pengetahuan sedang dan tidak ada gejala penyakit kulit sebanyak 18 orang $(25,7 \%)$. Pemulung yang memiliki pengetahuan baik yang mengalami sakit kulit yaitu sebanyak $4(5,7 \%)$ dan pemulung memiliki pengetahuan baik dan tidak mengalami gejala sakit kulit yaitu sebanyak 7 orang $(10,0 \%)$. Berdasarkan hasil penelitian terhadap 70 pemulung didapatkan 38 orang mengalami gejala sakit kulit dan 32 orang tidak mengalami sakit kulit.

Berdasarkan hasil uji statistik $C h i$ Square diperoleh nilai $\mathrm{p}=0,029<\mathrm{a}$ $(0,05)$, yang berarti Ho ditolak dan Ha diterima yang menunjukkan ada hubungan signifikan antara pengetahuan personal hygiene dengan gejala penyakit kulit pada pemulung di TPA sampah Suwung Denpasar dengan tingkat hubungan yang rendah yaitu dengan nilai $\mathrm{CC}=$ 0,304

\section{Pembahasan}

1. Pengetahuan personal hygiene pemulung di TPA sampah Suwung Denpasar.

Tingkat pendidikan seseorang akan memiliki andil besar dalam pola pikir dan masalah kesehatan. Tingkat pendidikan juga menentukan pengetahuan terhadap sesuatu khususnya pengetahuan tentang kondisi lingkungan dalam penanganan keluhan penyakit kulit. 
Tingkat pendidikan pemulung di TPA sampah Suwung yang lulusan SD sebanyak 39 orang $(55,7 \%)$ SMP sebanyak 19 orang $(27,1 \%)$ SMA sebanyak 1 orang $(1,4 \%)$ dan yang tidak sekolah sebanyak 11 orang $(15,7 \%)$.

Menurut Notoatmodjo (5), tingkat pendidikan seseorang dapat meningkatkan pengetahuannya, termasuk pengetahuan tentang kesehatan. Semakin tinggi pendidikan seseorang, maka semakin tahu bagaimana cara pencegahan dan penularan penyakit kulit. Pengetahuan seseorang akan berbeda-beda, biasanya diperoleh melalui pengalaman yang berasal dari berbagai sumber seperti lingkungan sekitar, keluarga, media masa, televisi maupun bangku pendidikan dan lainnya. Pengetahuan personal hygiene pada pemulung sangat penting diketahui, hal ini berguna untuk mencegah pemulung tertular dari penyakit kulit dan penyakit menular lainnya karena sampah.

Menurut Sajida (6), semakin bertambahnya umur seseorang maka akan mempengaruhi kemampuan berfikir, baik dalam menerima atau menangkap informasi yang diberikan oleh orang lain. Orang yang berpendidikan lebih tinggi biasanya bertindak lebih rasional, oleh karena itu orang yang berpendidikan lebih tinggi akan lebih mudah menerima gagasan baru.

Berdasarkan hasil penelitian terhadap pengetahuan personal hygiene diperoleh sebanyak 70 orang pemulung di Tempat Pembuangan Akhir sampah Suwung Denpasar didapatkan hasil sebanyak 27 $(38,6 \%)$ orang masuk dalam kategori buruk, kategori sedang sebanyak 32 orang $(45,7 \%)$ dan kategori baik sebanyak 11 orang $(15,7 \%)$. Pengetahuan seseorang berkaitan dengan tingkat pendidikan dan umur seseorang tersebut, dimana rata-rata umur pemulung di TPA sampah Suwung Denpasar adalah 31-40 tahun dan rata-rata pemulung tersebut hanya lulusan SMP dan SD. Pengetahuan personal hygiene pemulung di TPA sampah Suwung masuk dalam kategori sedang, tetapi berdasarkan pengamatan langsung pada pemulung, terlihat bahwa pengaplikasian pengetahuan mereka tentang personal hygiene masih kurang, terlihat bahwa mereka tidak mencuci pakian setelah digunakan hanya menggantungnya saja. Hal tersebut tentunya sangat berisiko mengingat paparan yang terjadi di tempat kerja yang penuh dengan sampah, akan menempel dan terdapat dipakaian bila tidak diganti akan membuat paparan ke kulit semakin lama dan akan meningkatkan gangguan kulit.

Dalam penelitian Sajida (6), menyatakan bahwa tingkat pendidikan seseorang akan memiliki andil besar terhadap pola pikir seseorang, selain itu tingkat pendidikan juga menentukan pengetahuan terhadap sesuatu hal khususnya pengetahuan kebersihan lingkungan yang tentunya juga akan menentukan kesehatan. Pengetahuan sejalan dengan perkembangan teknologi dan selalu mengalami pembaharuan maka dari itu seseorang harus melakukan apa yang mereka telah terlebih dahulu ketahui dan melakukan yang telah menjadi kebiasaan dan menjadi pengalaman mereka. 
2. Gejala penyakit kulit pada pemulung di TPA sampah Suwung Denpasar

Gejala Penyakit kulit adalah gangguan kulit yang muncul sebelum terjadinya penyakit kulit itu sendiri berupa rasa gatal-gatal, kulit kemerahan, muncul bintik-bintik merah/ bentol-bentol, yang berisi cairan bening ataupun nanah pada kulit yang gatal tersebut sehingga timbul ruam-ruam pada permukaan tubuh (7).

Berdasarkan hasil penelitian yang dilakukan dari 70 orang pemulung di TPA sampah Suwung diukur menggunakan kuisioner dan lembar pengamatan yang berisi pertanyaan yang berhubungan dengan gejala kulit, dari hasil penelitian menunjukkan hasil bahwa pemulung di TPA sampah Suwung Denpasar mengalami gejala penyakit kulit dari total 70 orang pemulung mendapatkan hasil sebanyak 38 orang $(54,3 \%)$ mengalami gejala penyakit kulit dan 32 orang $(45,7 \%)$ pemulung tidak mengalami gejala penyakit kulit. Gejala-gejala yang dilihat pada pemulung di TPA sampah Suwung Denpasar merupakan gejala primer dan sekunder yang umum terjadi sebelum terkena penyakit kulit tersebut seperti gatal-gatal, bercak merah, bentol-bentol, kulit kemerahan yang disertai dengan rasa panas, kulit bersisik dan kulit mengelupas.

Berdasarkan hasil pengamatan di lapangan mendapatkan hasil yaitu gejala penyakit kulit yang paling sering dialami oleh pemulung adalah gatal-gatal pada bagian tangan, kaki atau leher sebanyak 48 orang $68,6 \%$ dan 22 orang $31,4 \%$ tidak mengalami gatal-gatal, selanjutnya dari 70 orang terdapat 48 orang $68,6 \%$ yang terdapat bentol-bentol pada kulit dan
22 orang $31,4 \%$ tidak mengalami bentol-bentol, selanjutnya dari 70 orang terdapat 42 orang $60,0 \%$ yang memiliki kulit bersisik dan 28 orang $40,0 \%$ yang tidak, selanjutnya dari 70 orang terdapat 40 orang $57,1 \%$ yang mengalami kulit mengelupas dan 30 orang $42,8 \%$ yang tidak, selanjutnya dari 70 orang terdapat 41 orang $58,6 \%$ yang mengalami kulit kemerahan dan 29 orang 41,4\% yang tidak mengalami, selanjutnya dari 70 orang terdapat 34 orang $48,6 \%$ terdapat bercak-bercak merah dan 36 orang $51,4 \%$ tidak mengalami bercak-bercak merah. Hal ini dikarenakan pemulung yang banyak melakukan kontak langsung dengan sampah tanpa menggunakan alat pelindung diri seperti sarung tangan untuk melindungi tangannya selain itu perilaku mencuci tangan pemulung ini masih sangat kurang. Apabila diurutkan berdasarkan gejala penyakit kulti yang paling sering dialami oleh pemulung di TPA Suwung adalah gatal-gatal pada kulit, bentol-bentol pada kulit, kulit bersisik, kulit kemerahan, kulit mengelupas, dan bercak-bercak merah pada kulit.

Menurut Harahap (8), salah satu penyebab gangguan kulit yaitu pekerjaan dan kebersihan perorangan yang kurang baik. Untuk memelihara kebersihan kulit, kebiasaankebiasaan yang sehat harus selalu diperhatikan sepeti mandi secara teratur setiap harinya, menjaga kebersihan pakaian, mandi menggunakan air yang bersih dan sabun, menggunakan barang-barang keperluan sehari-hari sendiri, makan makanan yang bergizi terutama banyak buah dan sayur dan menjaga kebersihan lingkungan. 
3. Hubungan pengetahuan mengenai personal hygiene dengan gejala penyakit kulit pada pemulung di TPA Suwung Denpasar

Pengetahuan

menurut

Notoatmodjo (5), merupakan hasil dari tahu dan ini terjadi setelah orang melakukan pengindraan terhadap suatu objek tertentu. Pengindraan terjadi melalui panca indra manusia, yakni indra penglihatan, pendengaran, penciuman, rasa dan raba. Sebagian besar pengetahuan manusia diperoleh melalui mata dan telinga. Pengetahuan atau ranah kognitif merupakan domain yang sangat penting dalam membentuk tindakan seorang (overt behavior).

Hasil penelitian yang dilakukan di Tempat Pembuangan Akhir Sampah Suwung Denpasar terhadap pemulung mengenai hubungan pengetahuan personal hygiene dengan gejala penyakit kulit, dari hasil uji statistik Chi Square memeperoleh nilai $\mathrm{p}=0,029<\mathrm{a}$ $(0,05)$, yang berarti Ho ditolak dan Ha diterima yang berarti terdapat hubungan signifikan antara pengetahuan personal hygiene dengan gejala penyakit kulit pada pemulung di TPA Suwung dengan tingkat hubungan yang lemah, dengan nilai yang diperoleh $\mathrm{CC}=$ 0,304. Dari hasil tersebut menunjukkan bahwa semakin rendah tingkat pengetahuan pemulung terkait dengan personal hygiene, maka semakin tinggi resiko mengalami gejala penyakit kulit. Begitu juga sebaliknya semakin tinggi tingkat pengetahuan pemulung terkait dengan personal hygiene maka semakin rendah pula resiko mengalami gejala penyakit kulit. Pengetahuan personal hygiene pada pemulung di TPA Suwung
Denpasar memiliki hubungan yang lemah terhadap gejala penyakit kulit dikarenakan penggetahuan mengenai personal hygiene bukan merupakan faktor sesorang terkena gejala penyakit kulit, masih banyak faktorfaktor pengganggu lainnya yang dapat menjadi faktor yang menyebabkan terjadinya gejala penyakit kulit tersebut seperti lama kerja, umur dari responden tersebut, daya tahan tubuh, tindakan dari pemulung tersebut dan salah satunya yang berpengaruh adalah riwayat alergi dari pemulung tersebut.

Bila dilihat dari hasil penelitian masa kerja pemulung dengan kategori 1-10 tahun paling banyak mengalami gejala penyakit kulit sebanyak 28 orang (59\%) hal tersebut dikarenakan pada awal bekerja pemulung merasakan keluhan gangguan penyakit kulit yang bermacam-macam gatal-gatal dan kulit kemerahan sehingga tahun berikutnya mereka sudah kebal terhadap keluhan gangguan penyakit kulit tersebut.

\section{Simpulan}

Berdasarkan hasil penelitian simpulannya adalah sebagai berikut:

1. Pengetahuan personal hygiene pemulung di TPA sampah Suwung Denpasar, yaitu dengan kategori baik sebanyak 11 orang $15,7 \%$, pengetahuan sedang sebesar 32 orang $45,7 \%$ dan pengetahuan buruk sebesar 27 orang $38,6 \%$

2. Gejala penyakit kulit pada pemulung di TPA sampah Suwung Denpasar, yaitu ada gejala penyakit kulit sebesar 38 orang $(54,3 \%)$ dan tidak ada gejala penyakit kulit sebesar 32 orang $(45,7 \%)$. Gejala penyakit kulit yang paling sering dialami 
pemulung adalah gatal-gatal, bentol-bentol, kulit bersisik, kulit kemerahan, kulit mengelupas, dan bercak-bercak merah pada kulit.

3. Ada hubungan yang signifikan antara pengetahuan personal hygiene dengan gejala penyakit kulit pada pemulung di TPA Suwung Denpasar (nilai $\mathrm{p}=$ $0,029<a(0,05)$ dengan tingkat hubungan lemah $(\mathrm{CC}=0,304)$. Pengetahuan personal hygiene bukan merupakan faktor utama terjadi penyakit kulit, tapi masih ada faktor-faktor lain yang mempengaruhi seperti riwayat alergi, usia, daya tahan tubuh dan lama kerja

\section{Saran}

Berdasarkan simpulan di atas, maka saran yang dapat disampaikan yaitu:

1. Kepada pemulung di TPA sampah Suwung Denpasar, agar lebih memperhatikan perilaku hidup bersih dan sehat dengan mandi secara teratur, mencuci tangan menggunakan air bersih dan mencuci pakaian kerja setelah bekerja.

2. Kepada pengepul pampah, agar lebih meperhatikan kesehatan para pemulungnya dan menyarankan melakukan cek kesehatan secara berkala.

3. Puskesmas IV Denpasar Selatan, agar memberikan penyuluhan pemulung di sekitar TPA sampah Suwung Denpasar mengenai personal hygiene dalam rangka mengatasi keluhan gangguan kulit.

\section{Daftar Pustaka}

1. Abbas S. Gambaran Penyakit Kulit Pada Petani Tambak di Desa Salipolo Kecamatan Cempa Kabupaten Pinrang. In: UMI Makassar. 2013.

2. Suprapto. Dampak Masalah Sampah Terhadap Kesehatan Masyarakat. Mutiara Kesehat Indones. 2005;1.

3. Saputra. Penyakit Kulit Akibat Kerja Pada Pemulung di Tempat Pembuangan Sampah Akhir Suwung Denpasar Selatan. In: FKM Unud. 2016.

4. Notoatmodjo. Metodologi Penelitian Kesehatan. In: PT Rineka Cipta Jakarta. 2012.

5. Notoatmodjo. Promosi Kesehatan dan Prilaku Kesehatan. In: PT Rineka Cipta Jakarta. 2012.

6. Sajida A. Hubungan Personal Hygiene dan Sanitasi Lingkungan dengan Keluhan Penyakit Kulit di Kelurahan Denai Kecamatan Medan Denai Kota Medan. In 2012.

7. Graham R. Lecture Notes Dermatologi. In: Erlangga Jakarta. 2005.

8. Harahap. Ilmu Penyakit Kulit. In: Hipokrates Jakarta. 1998. 